\title{
Evidence of Hydrogen Sulfide Involvement in Amyotrophic Lateral Sclerosis
}

\author{
Alessandro Davoli, MD, ${ }^{1}$ Viviana Greco, PhD, ${ }^{2,3}$ Alida Spalloni, PhD, ${ }^{4}$ \\ Ezia Guatteo, PhD, ${ }^{5}$ Cristina Neri, PhD, ${ }^{2,3}$ Giada Ricciardo Rizzo, MD, ${ }^{1}$ \\ Alberto Cordella, MD, ${ }^{5}$ Andrea Romigi, MD, ${ }^{1}$ Claudio Cortese, $\mathrm{PhD},{ }^{2}$ \\ Sergio Bernardini, PhD, ${ }^{2}$ Paola Sarchielli, MD, ${ }^{6}$ Gabriela Cardaioli, MD, ${ }^{6}$ \\ Paolo Calabresi, MD, ${ }^{6,7}$ Nicola B. Mercuri, MD, ${ }^{1,5}$ Andrea Urbani, PhD, ${ }^{2,3}$ and \\ Patrizia Longone, $\mathrm{PhD}^{4}$
}

Objective: Amyotrophic lateral sclerosis (ALS) is a motor neuron disease whose pathophysiological deficits, causing impairment in motor function, are largely unknown. Here we propose that hydrogen sulfide $\left(\mathrm{H}_{2} \mathrm{~S}\right)$, as a $\mathrm{glial}$-released inflammatory factor, contributes to ALS-mediated motor neuron death.

Methods: $\mathrm{H}_{2} \mathrm{~S}$ concentrations were analyzed in the cerebrospinal fluid of 37 sporadic ALS patients and 14 age- and gender-matched controls, in tissues of a familial ALS (fALS) mouse model, and in spinal cord culture media by means of a specific and innovative high-performance liquid chromatography method. The effects of $\mathrm{H}_{2} \mathrm{~S}$ on motor neurons cultures was analyzed immunohistochemically and by patch clamp recordings and microfluorometry.

Results: We found a significantly high level of $\mathrm{H}_{2} \mathrm{~S}$ in the spinal fluid of the ALS patients. Consistently, we found increased levels of $\mathrm{H}_{2} \mathrm{~S}$ in the tissues and in the media from mice spinal cord cultures bearing the fALS mutation SOD1G93A. In addition, NaHS, an $\mathrm{H}_{2} \mathrm{~S}$ donor, added to spinal culture, obtained from control C57BL/6J mice, is toxic for motor neurons, and induces an intracellular $\mathrm{Ca}^{2+}$ increase, attenuated by the intracytoplasmatic application of adenosine triphosphate. We further show that $\mathrm{H}_{2} \mathrm{~S}$ is mainly released by astrocytes and microglia.

Interpretation: This study unravels $\mathrm{H}_{2} \mathrm{~S}$ as an astroglial mediator of motor neuron damage possibly involved in the cellular death characterizing ALS.

ANN NEUROL 2015;77:697-709

A myotrophic lateral sclerosis (ALS) is a lethal disease characterized by a progressive upper and lower motor neuron degeneration, which leads to a rapid weakness of muscles and wasting. ${ }^{1,2}$ Although the pathological processes affecting motor neurons are largely unknown, many factors have been implicated in the cellular damage. These include excitatory amino acid neurotoxicity, microglia-dependent inflammation, engulfment by misfolded protein, dysfunctional axonal transport systems, and mutations in RNA binding proteins. ${ }^{3,4}$ In any case, it is generally accepted that a severe mitochondrial dysfunction finally leads to unavoidable neuronal death. ${ }^{5}$ Despite this, there is no certainty on the intimate mechanisms sustaining the progressive loss of motor neurons. Therefore, there is a need, at both the preclinical and clinical level, to progress the available knowledge on this disease, either by better deciphering the processes involved in the neuronal demise or by individuating valid

View this article online at wileyonlinelibrary.com. DOI: 10.1002/ana.24372

Received Oct 14, 2014, and in revised form Jan 15, 2015. Accepted for publication Jan 17, 2015

Address correspondence to Dr Longone, Molecular Neurobiology Unit, IRCCS-Fondazione Santa Lucia, 00143 Rome, Italy.

E-mail: p.longone@hsantalucia.it

From the ${ }^{1}$ Neurophysiopathology Unit; ${ }^{2}$ Department of Experimental Medicine and Surgery, Department of System Medicine, University of Rome Tor Vergata, Rome; ${ }^{3}$ Proteomics and Metabonomics Unit; ${ }^{4}$ Molecular Neurobiology Unit; ${ }^{5}$ Experimental Neurology Unit, Institute of Hospitalization and Scientific Care-Fondazione Santa Lucia, Rome; ${ }^{6}$ Neurological Clinic, Department of Medicine, University of Perugia, Ospedale Santa Maria della Misericordia, Perugia; and ${ }^{7}$ Neurophysiology Unit, Institute of Hospitalization and Scientific Care-Fondazione Santa Lucia, Rome, Italy 
biomarkers that are able to assist the diagnosis, giving additional hints on the damaging mechanisms. ${ }^{6}$

Hydrogen sulfide $\left(\mathrm{H}_{2} \mathrm{~S}\right)$, a colorless gas with an unpleasant odor, considered a toxic environmental pollutant, is now recognized, along with nitric oxide and carbon monoxide, as an important endogenous neuromodulator. ${ }^{7}$ Three enzymes have been identified as $\mathrm{H}_{2} \mathrm{~S}$ producers in mammalian tissues: cystathionine- $\beta$ synthase (CBS) and cystathionine- $\gamma$-lyase $(\gamma$-cystathionase [CSE]) from L-cysteine, ${ }^{8,9}$ and 3-mercaptopyruvate sulfurtransferase (3MST) in combination with cysteine aminotransferase. 9 Whereas CBS and 3MST are preferentially expressed in the central nervous system, CSE is localized mainly in the peripheral tissues. ${ }^{11,12}$ Astrocytes are the main cells that generate $\mathrm{H}_{2} \mathrm{~S},{ }^{13}$ and the regulation of its synthesis seems to be closely associated with increasing intracellular level of $\mathrm{Ca}^{2+} \cdot{ }^{14}$ Moreover, physiological stimuli and L-glutamate greatly enhance $\mathrm{H}_{2} \mathrm{~S}$ production. ${ }^{14}$ In astrocytes, $\mathrm{H}_{2} \mathrm{~S}$ induces $\mathrm{Ca}^{2+}$ influx that propagates to the surrounding astrocytes as $\mathrm{Ca}^{2+}$ waves. ${ }^{15,16}$ In different types of cells, including neurons, vascular smooth muscle cells, cardiomyocytes, and pancreatic $\beta$-cells, $\mathrm{H}_{2} \mathrm{~S}$ stimulates the activity of the adenosine triphosphate-sensitive potassium channels. ${ }^{17-19}$

In the central nervous system, $\mathrm{H}_{2} \mathrm{~S}$ attenuates the neuroinflammatory processes induced by lipopolysaccharide $(\mathrm{LPS})^{20}$ and amyloid- $\beta .^{21}$ It suppresses oxidative stress induced by hydrogen peroxide, ${ }^{22}$ and protects cells against the neurotoxins rotenone ${ }^{23}$ and 6-hydroxydopamine. ${ }^{24}$ The protective effects of $\mathrm{H}_{2} \mathrm{~S}$ have been established also in vivo in animal models of Parkinson ${ }^{25,26}$ and Alzheimer ${ }^{27,28}$ diseases, as well as in models of cerebral ischemia. ${ }^{29,30}$ Conversely, some studies have described an increased neuronal death and recruitments of death-inducing pathways (apoptosis and necrosis) in the presence of $\mathrm{H}_{2} \mathrm{~S}$, even at physiological concentrations. It has been demonstrated that $\mathrm{H}_{2} \mathrm{~S}$ exacerbates glutamate-mediated toxicity ${ }^{31}$ and raises intracellular calcium into the toxic range in a dose-dependent manner via the activation of L-type $\mathrm{Ca}^{2+}$ channels and $\mathrm{N}$ methyl-D-aspartate (NMDA) receptors. ${ }^{32}$ Hence, $\mathrm{H}_{2} \mathrm{~S}$ has been proposed as an important modulator of $\mathrm{Ca}^{2+}$ homeostasis and consequently of neuronal functions.

In an effort to understand the role of $\mathrm{H}_{2} \mathrm{~S}$ in neurodegeneration and specifically in ALS, we undertook an unbiased observational clinical study measuring this molecule in the plasma and in the spinal fluids of ALS patients (male and female) and age- and gendermatched controls. We then measured its concentration in the SOD1G93A mouse, a familial ALS (fALS) animal model, and in the extracellular milieu of SOD1G93A spinal cultured neurons. Finally, we assessed its effects on neuronal survival and intracellular $\mathrm{Ca}^{2+}$ concentration.

\section{Materials and Methods}

\section{Study Population: Patients and Controls and Ethics Statement}

To exclude other neurological diseases, lumbar puncture was performed in 37 of 81 patients who were followed at the neurologic clinics of the University of Rome Tor Vergata and University of Perugia.

Lumbar puncture (between L4 and L5 or L3 and L4 lumbar space) was performed following the guidelines of the local ethical committees for routine neurological investigations. Written consent was obtained from each patient, and the liquor was stored. We later asked for permission to detect $\mathrm{H}_{2} \mathrm{~S}$, but the majority of patients (26 of 37 ) had died. For this study, we enrolled a total of 37 sporadic ALS patients ( 21 male, 16 female) and 14 age- and gender-matched controls (6 male and 8 female). ALS patients were diagnosed according to the revised El Escorial criteria, showing patients with definite $(n=5)$, probable $(n=17)$, possible $(n=10)$, or suspected $(n=5)$ ALS on initial diagnosis and later confirmed as definite ALS. Onset was bulbar onset $(\mathrm{BO} ; \mathrm{n}=10)$ or limb onset ( $\mathrm{LO} ; \mathrm{n}=27)$; we further divided the LO group into 2 subgroups, upper limb onset (ULO; $\mathrm{n}=8$ ) and lower limb onset (LLO; $\mathrm{n}=19$ ). The median score of the revised ALS functional rating scale of ALS patients was 40.0 (37.0-44.0 as 25 th -75 th percentile). The median score of the disease duration expressed in months was 9.0 (7.0-12.0). Moreover, we calculated the progression rate, defined using previously published criteria (Amyotrophic Lateral Sclerosis Functional Rating Scale-Revised [ALSFRS-R]/disease duration in months), ${ }^{33}$ showing a median score of $0.87(0.44-1.11)$. None of the ALS patients had signs or symptoms of respiratory insufficiency, all patients had $>70 \%$ predicted forced vital capacity, and normal daytime gas exchange. All ALS patients were riluzole naive and sporadic, without a family history of ALS. All control patients had no neurodegenerative diseases and based on extensive diagnostic evaluation, had no objective clinical, structural (cranial magnetic resonance imaging), laboratory (cerebrospinal fluid [CSF] analysis), or functional (electroencephalography) deficit, suffering predominantly from headache (spondylogenic or nonspecific), lower back pain, dizziness or vestibular vertigo, and psychiatric disorders. The Table illustrates the characteristics of the patients' population and controls.

Serum samples were collected during routine diagnostic investigations as indicated by the treating physicians. Samples of CSF and blood were collected in the morning, kept at $4^{\circ} \mathrm{C}$, and processed within 2 hours. Serum and CSF samples were spun simultaneously at $2,000 \times g$ at $4^{\circ} \mathrm{C}$ for 10 minutes, aliquoted in polypropylene tubes, and stored at $-80^{\circ} \mathrm{C}$ until assay. All samples were obtained with the identical procedure.

\section{Animals and Ethics Statement}

Transgenic SOD1G93A mice maintained in the C57BL/6J background (for $>10$ generations) and nontransgenic C57BL/ 
6J littermates were used in the study. The B6SJL-TgN (SOD1G93A) 1Gur mice were from our own colony, bred at the Saint Lucia Foundation animal facility, and originally obtained from the Jackson Laboratories (Bar Harbor, ME). All experiments were conducted in compliance with European Council Directive 86/609/EEC and the Italian Animal Welfare Act for the use and care of laboratory animals.

Animals with considerable motor impairment were provided food and water on the cage bottom. Before proceeding to the dissection of tissues for biochemical analyses, the mice were deeply anesthetized and then sacrificed by decapitation.

Screening for the presence of the human transgene was performed as previously described. ${ }^{34}$

\section{$\mathrm{H}_{2} \mathrm{~S}$ Measurement by High-Performance Liquid Chromatography}

We developed specific and innovative high-performance liquid chromatography (HPLC) tests to measure $\mathrm{H}_{2} \mathrm{~S}$ levels in biological fluids (CSF and serum), tissues, and spinal cord cultures. HPLC with electrochemical detection is a sensitive approach that can be used for the direct measurement of thiols and sulfides without the problems of sample dilution, reaction kinetics, and reaction efficiency often associated with derivatization procedures.

Briefly, the samples (CSF, sera, and tissues) were prepared according to a standard procedure described by Bailey et $\mathrm{a}^{35}$ with modifications. The HPLC system used to measure $\mathrm{H}_{2} \mathrm{~S}$ consisted of an autosampler, an isocratic pump (Dionex ICS 3000; Thermo Fisher Scientific, Waltham, MA), and an amperometric detector. The chromatographic separation was achieved using the IonPac AS15-5 $\mu$ m Analytical Column $(3 \times 150 \mathrm{~mm})$ in combination with the AG15 guard column $(3 \times 30 \mathrm{~mm})$. The mobile phase consisted of $75 \mathrm{mM} \mathrm{NaOH}$ generated by a Sodium Hydroxide Eluent Generator Cartridge (Dionex; Thermo Fisher Scientific), prepared daily, filtered, and sonicated. The flow rate was $0.5 \mathrm{ml} / \mathrm{min}$. The injected volume was $25 \mu$ l. The detection of sulfide was performed by a disposable silver working electrode and $\mathrm{Ag} / \mathrm{AgCl}$ reference electrode.

All instrument control, data acquisition, and data analysis were performed using Chromeleon software (v6.8, Dionex, Thermo Fisher Scientific).

\section{Tissue Collection, Mitochondria-Enriched Frac- tion Preparation, and Western Blot Analysis}

The crude mitochondrial fraction was prepared following Malkus and Ischiropoulos. ${ }^{36}$ Following a first centrifugation at $6,800 \times g$ for 15 minutes at $4^{\circ} \mathrm{C}$, the pellets were washed with sucrose, and the supernatants were centrifuged at 21,000 $\times g$ for 30 minutes at $4^{\circ} \mathrm{C}$. The resulting supernatant was retained as the cytoplasmic fraction. The pellet, which contained the light mitochondria and lysosomes (light $\mathrm{M}+\mathrm{L}$ fraction), was washed with sucrose and resuspended in $0.25 \mathrm{M}$ Sucrose. The mitochondria were then precipitated out of the $\mathrm{M}+\mathrm{L}$ fraction by incubation with $115 \mu \mathrm{M} \mathrm{CaCl}_{2}$ for 30 minutes. The sample was then centrifuged $5,000 \times g$ for 10 minutes at $4{ }^{\circ} \mathrm{C}$ to pellet the mitochondria. The samples, loaded on $10 \%$ sodium dodecyl sulfate polyacrylamide gel electrophoresis and transferred to polyvinylidene difluoride membrane (Invitrogen, Carlsbad, CA), were probed with a primary antibody against CBS (Santa Cruz Biotechnology, Santa Cruz, CA; 1:100), visualized with enhanced chemiluminescence (ECL Plus; Amersham, Piscataway, NJ), ${ }^{34}$ and analyzed using Image-Quant TL software (Amersham Biosciences, Piscataway, NJ). CBS immunoreactivity was normalized to beta-actin for the cytosolic fraction (Sigma-Aldrich, St Louis, MO; 1:20,000) and the voltagedependent anion-selective channel (VDAC) for the mitochondrial fraction (Cell Signaling Technology, Danvers, MA; 1:500).

\section{Spinal Cord Culture, Drug Treatments, and Immunohistochemistry}

Mixed spinal cord cultures were prepared largely as previously described $^{37}$ from 13.5-day-old embryos of a control C57BL/6J female mated with a SOD1G93A male. Each neural tube was dissected singularly, and the resulting mixed cultures were seeded on poly-L-lysine-coated glass cover slips (3 cover slips for each spinal cord/dish) Experiments on spinal cord cultures were performed between 12 and 15 days in vitro (DIV), unless otherwise indicated. After plating, the embryos were analyzed for the presence of the human SOD1 gene. To suppress glia proliferation, 3 days after seeding, arabinoside C (Ara-C; $10 \mu \mathrm{M})$ was added to each well. LPS $(100 \mathrm{ng} / \mathrm{ml})$ treatment was performed 3 days after plating for 24 hours, and then the medium was replaced with fresh medium.

Spinal cord cultures were exposed to the $\mathrm{H}_{2} \mathrm{~S}$ donor $\mathrm{NaHS}$, following Cheung et al. ${ }^{31}$ When indicated during $\mathrm{H}_{2} \mathrm{~S}$ exposure, the NMDA receptor antagonist MK-801 $(10 \mu \mathrm{M})$, the $\alpha$-amino-3-hydroxy-5-methyl-4-isoxazole propionic acid (AMPA) receptor antagonist 6-cyano-7-nitroquinoxaline-2,3dione $(\mathrm{CNQX} ; 25 \mu \mathrm{M})$, and the voltage-gated $\mathrm{Na}^{+}$channel blocker tetrodotoxin (TTX; $1 \mu \mathrm{M})$ were added. Cultures were then stained with SMI-32 (Covance, Princeton, NJ; 1:1,000) to visualize motor neurons, glial fibrillary acidic protein (GFAP; Millipore, Billerica, MA; $1: 1,000)$ to visualize astrocytes and $\gamma$ aminobutyric acid (GABA; Sigma, St Louis, MO; 1:500) to visualize GABAergic neurons. SMI-32 and GABA positive cells were quantified by direct counting, and their number was normalized to the untreated spinal cord preparation.

\section{Patch Clamp Recordings and Microfluorometry}

Patch clamp recordings combined with microfluorometry were performed according to published procedures. ${ }^{38}$ Extracellular solution contained (in $\mathrm{mM}$ ): $126 \mathrm{NaCl}, 2.5 \mathrm{KCl}, 1.2 \mathrm{MgCl}_{2}$, $1.2 \mathrm{NaH}_{2} \mathrm{PO}_{4}, 2.4 \mathrm{CaCl}_{2}, 10$ glucose, and $24 \mathrm{NaHCO}_{3}, 290$ mOsm-1, and was gassed with $95 \% \mathrm{O}_{2}-5 \% \mathrm{CO}_{2}, \mathrm{pH}$ 7.4. DAmino-phosphonovalerate (APV; $50 \mu \mathrm{M})$, 2,3-dihydro-6-nitro7-sulphamoyl-benzo(F)quinoxaline (NBQX) $10 \mu \mathrm{M}$, TTX, or lidocaine $(1 \mu \mathrm{M}$ or $200 \mu \mathrm{M}$, respectively) were added to prevent calcium entry through NMDA or AMPA receptors, and action potential-dependent glutamate release by surrounding neurons, respectively.

Intracellular solution contained (in $\mathrm{mM}$ ): $140 \mathrm{CsCl}, 0.75$

EGTA, 10 HEPES, 6 D-glucose, and 0.25 fura-2 
TABLE . Patients Characteristics

\begin{tabular}{|c|c|c|c|c|c|}
\hline \multirow[t]{3}{*}{ Characteristic } & \multicolumn{5}{|c|}{ Diagnostic Group } \\
\hline & \multirow[t]{2}{*}{ ALS } & \multirow[t]{2}{*}{ Controls } & \multirow[t]{2}{*}{ ALS-BO } & \multicolumn{2}{|c|}{ ALS-LO } \\
\hline & & & & ALS-ULO & ALS-LLO \\
\hline No. & 37 & 14 & 10 & 8 & 19 \\
\hline Age, $\mathrm{yr}^{\mathrm{a}}$ & $65.7 \pm 10.4$ & $59.2 \pm 12.4$ & $63.6 \pm 12.2$ & $60.3 \pm 13.3$ & $69.1 \pm 6.8$ \\
\hline Sex, F/M & $16 / 21$ & $8 / 6$ & $4 / 6$ & $3 / 5$ & $9 / 10$ \\
\hline Disease duration, $\mathrm{mo}^{\mathrm{b}}$ & $9.0(7.0-12.0)$ & $\mathrm{N} / \mathrm{A}$ & $8.0(7.0-10.0)$ & $12.0(9.0-18.5)$ & $10.0(7.0-12.0)$ \\
\hline ALSFRS-R score ${ }^{b}$ & $40.0(37.0-44.0)$ & $\mathrm{N} / \mathrm{A}$ & $42.5(38.0-44.0)$ & $40.0(37.0-43.5)$ & $40.0(36.0-44.0)$ \\
\hline Progression rate ${ }^{b}$ & $0.87(0.44-1.11)$ & $\mathrm{N} / \mathrm{A}$ & $0.64(0.37-1.11)$ & $0.59(0.33-0.93)$ & $1.0(0.5-1.25)$ \\
\hline \multicolumn{6}{|c|}{$\begin{array}{l}\text { Progression rate: mean ALSFRS-R monthly decline }=(48-\text { ALSFRS-R }) / \text { disease duration in months). The ALS group has been fur- } \\
\text { ther divided into } 2 \text { subgroups: ALS-BO and ALS-LO. The ALS-LO subgroup has been subdivided into ALS-ULO and ALS-LLO. } \\
{ }^{a} \text { Data are expressed as mean age } \pm \text { standard deviation. } \\
{ }^{b} \text { Data are expressed as median }(25 \text { th- } 75 \text { th percentile). } \\
\text { ALS = patients with amyotrophic lateral sclerosis; ALSFRS-R = Amyotrophic Lateral Sclerosis Functional Rating Scale-Revised; } \\
\text { BO = bulbar onset; F = female; LLO = lower limb onset; LO = limb onset; } M=\text { male; N/A = not applicable; ULO = upper limb } \\
\text { onset. }\end{array}$} \\
\hline
\end{tabular}

pentapotassium salt (Invitrogen), $\mathrm{pH}$ 7.3. When indicated, $2 \mathrm{mM}$ adenosine triphosphate (ATP) was added to this solution. Experiments were performed at $32^{\circ} \mathrm{C}$.

Fura-2AM loading $(10 \mu \mathrm{M}$, Invitrogen) was achieved by dissolving the dye in the medium for 30 minutes followed by 20 minutes in dye-free medium for de-esterification, in the dark at $32^{\circ} \mathrm{C}$. Ultraviolet excitation light (340 and 380nm) was provided by a monochromator (TILL Photonics, Gräfelfing, Germany). Emitted light passed a barrier filter (440nm) and was detected by charge-coupled device camera (Evolve; Photometrics, Tucson, AZ), and images were acquired at 3-second intervals using MetaFluor software. Fluorescence changes expressed as ratio $(R)$ were calculated from the formula $R=$ (F340soma-F340bg)/(F380soma-F380bg) as previously reported. ${ }^{39}$

Data were analyzed with Origin (v6; OriginLab, Northampton, MA), expressed as mean \pm standard error of the mean (SEM), and compared using 1- or 2-population Student $t$ test.

\section{Statistical Analysis}

All data are expressed as mean \pm SEM, and $p$ values $<0.05$ were considered statistically significant. For the statistical analysis of patients, nonparametric tests were used, because the data were not normally distributed; comparisons between $\mathrm{H}_{2} \mathrm{~S}$ concentrations in ALS group patients and controls were performed using the analysis of variance (ANOVA) Kruskal-Wallis test and post hoc Mann-Whitney $U$ test. We used Spearman rank correlation to check potential correlations between $\mathrm{H}_{2} \mathrm{~S}$ levels in ALS groups and the variables age, disease duration, ALSFRS$\mathrm{R}$ score, and progression rate.

The data obtained from the $\mathrm{H}_{2} \mathrm{~S}$ analysis in tissues and cell culture media were analyzed using the Wilcoxon-MannWhitney test. Changes in CBS expression and cytosolic $\mathrm{Ca}^{2+}$ concentration were assessed by Student $t$ test. Neuronal death in primary culture was assessed by ANOVA followed by the post hoc Tukey test for $\mathrm{N}$ unequal.

\section{Results}

\section{ALS Patients Displayed Increased $\mathrm{H}_{2} \mathrm{~S}$ Level in CSF}

We first sought to investigate whether $\mathrm{H}_{2} \mathrm{~S}$ levels were altered in the ALS patient samples (see the Table for patients characteristics). Liquoral $\mathrm{H}_{2} \mathrm{~S}$ concentration was significantly increased in patients with ALS compared to controls $(p<0.00001$; Fig 1). We further observed a relationship between liquoral $\mathrm{H}_{2} \mathrm{~S}$ content and the site of disease onset, with increasing levels in the craniocaudal direction $(\mathrm{BO}<\mathrm{ULO}<\mathrm{LLO})$. Significantly higher levels were found in the LO subgroups compared to the $\mathrm{BO}$ subgroup $(p<0.05)$. Moreover, $\mathrm{H}_{2} \mathrm{~S}$ concentration was elevated in the ULO subgroup compared with the LLO subgroup $(p=0.058)$. We also observed a gender difference with higher $\mathrm{H}_{2} \mathrm{~S}$ levels in the CSF of ALS female patients with respect to the male patients, although nonsignificantly (not shown). No correlations were found between liquoral $\mathrm{H}_{2} \mathrm{~S}$ concentration and age, duration of disease, or ALFRS-R score $(R=0.008 ; R=0.14$, and $R=0.20$ respectively). Conversely, $\mathrm{CSF} \mathrm{H}_{2} \mathrm{~S}$ values and progression rate were related in the ALS group $(R=0.33 ; p<0.05)$. Interestingly, no difference in $\mathrm{H}_{2} \mathrm{~S}$ blood levels between ALS patients and controls was seen (not shown). These results suggest that elevation of $\mathrm{H}_{2} \mathrm{~S}$ in ALS may be related to disease progression and/or pathogenesis. 

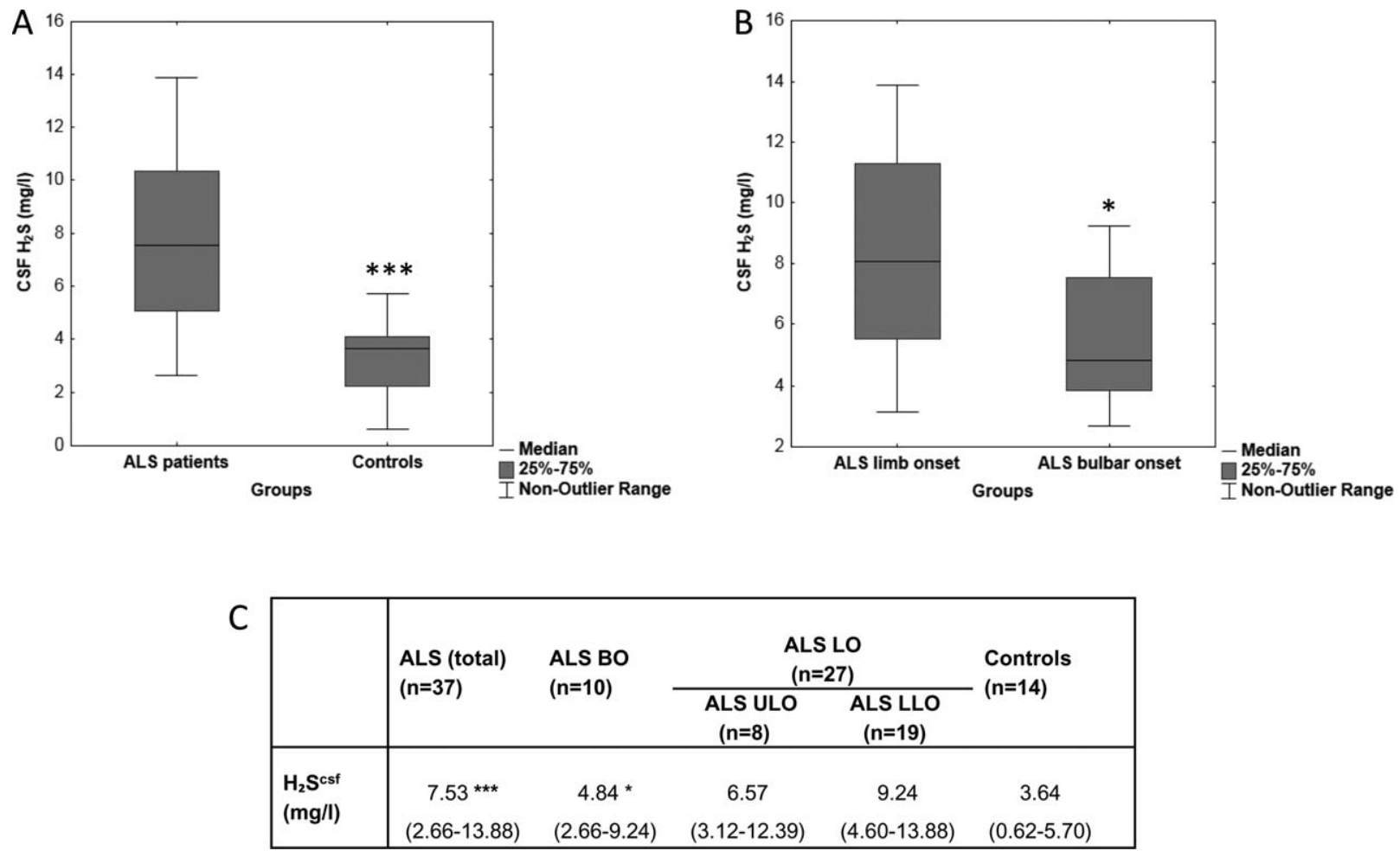

FIGURE 1: Hydrogen sulfide $\left(\mathrm{H}_{2} \mathrm{~S}\right)$ is increased in the cerebrospinal fluid (CSF) of amyotrophic lateral sclerosis (ALS) patients. Significant differences in $\mathrm{H}_{2} \mathrm{~S}$ levels were found (A) between median values in ALS patients $(n=37)$ compared to controls $\left(n=14 ;{ }^{* \star *} p<0.00001\right)$ and (B) between median values in ALS limb onset (LO; $\left.n=27\right)$ compared to ALS bulbar onset (BO; $\mathrm{n}=10$ ) groups $\left({ }^{*} p<0.05\right)$. Data were analyzed with the Mann-Whitney $U$ test. (C) The $\mathrm{H}_{2} \mathrm{~S}$ values (mg/l) in the CSF are presented as medians, with ranges in parentheses. The LO group was further divided in upper limb onset $(U L O=8)$ and lower limb onset (LLO $=19$ ). ${ }^{\star} A L S$ LO $>$ ALS $B O, p<0.05 ;{ }^{* \star *} A L S$ (total) $>$ controls, $p<0.00001$. [Color figure can be viewed in the online issue, which is available at wileyonlinelibrary.com.]

\section{fALS Mouse Model Harbors Increased $\mathrm{H}_{2} \mathrm{~S}$ in Neuronal Tissues}

We then conducted quantitative analyses of the $\mathrm{H}_{2} \mathrm{~S}$ content in cerebral tissues from the fALS mouse SOD1G93A, an established ALS animal model ${ }^{40}$ that essentially recapitulates the human form of the disease. $\mathrm{H}_{2} \mathrm{~S}$ concentrations found in the neuronal tissues of the wild-type (WT) mice were comparable with those present in the literature ${ }^{41}$ (Fig $2 \mathrm{~A}$, white bars). We performed a time course analysis and evaluated $\mathrm{H}_{2} \mathrm{~S}$ content at 90 (early symptomatic), 110 (symptomatic), and 130 days of age (end stage) and found a significant increase in $\mathrm{H}_{2} \mathrm{~S}$ content in the fALS mice compared to the age-matched WT mice.

We then analyzed the $\mathrm{H}_{2} \mathrm{~S}$ content in the male and female populations. We found significantly higher concentrations in the female mouse population at 110 and 130 days of age in all tissues analyzed (see Fig 2B). Moreover, we observed a significant steady increase of the $\mathrm{H}_{2} \mathrm{~S}$ levels within each group (male and female).

Lastly, we examined the amount and cellular localization of CBS. Highly expressed in the central nervous system, CBS is among the enzymes devoted to the production of $\mathrm{H}_{2} \mathrm{~S}$. It is a cytoplasmatic enzyme that accumulates in mitochondria under oxygen sensitive conditions. ${ }^{42}$ Variation in the enzyme expression might be due to the progressive weakness of the respiratory muscles ${ }^{43}$ and/or dysfunction of central respiratory drive. ${ }^{44}$ ALS patients frequently experience hypoxia, a well-described phenomenon in ALS. ${ }^{45-48}$ Compared to the age-matched controls, the accumulation of CBS in spinal cord mitochondria of SOD1G93A mice at end stage was remarkably elevated (Fig 3B; $p<0.01$ ).

\section{Abnormal $\mathrm{H}_{2} \mathrm{~S}$ Release in Mixed Spinal Cord Cultures from SOD1G93A Mice}

We then investigated whether mutant SOD1 overexpression boosts endogenous $\mathrm{H}_{2} \mathrm{~S}$ release in spinal cord cultures containing a mixed population of neuronal and glial cells.

The release of $\mathrm{H}_{2} \mathrm{~S}$ was examined in the media of spinal cord culture (12-15 DIV) prepared from the fALS mouse model and compared to WT littermates cultures. $\mathrm{H}_{2} \mathrm{~S}$ levels showed an overall significantly higher concentration in the mutant cultures (Fig 4A; $4.96 \mathrm{mg} / \mathrm{l}$ ) compared to the control cultures $(2.89 \mathrm{mg} / \mathrm{l})$. Astrocytes are the most important producers of $\mathrm{H}_{2} \mathrm{~S}$ in the brain. ${ }^{13}$ Thus, we also examined whether the inhibition of their growth had an effect on $\mathrm{H}_{2} \mathrm{~S}$ levels in the culture media. 
A

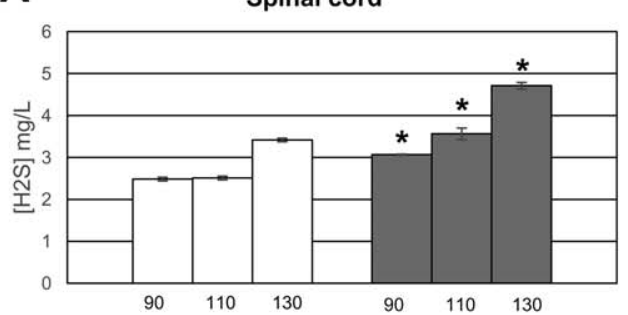

Brainstem

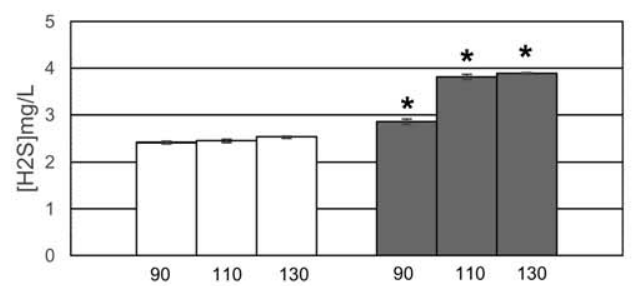

Motor cortex

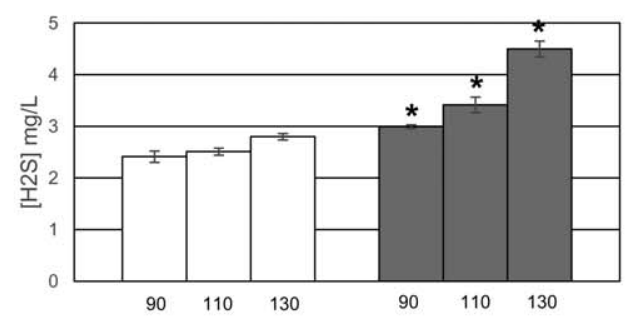

B

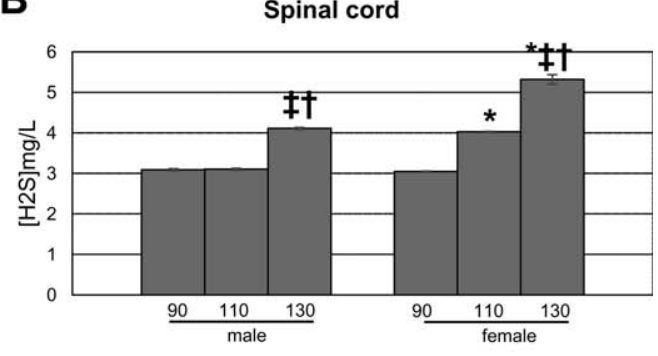

Brainstem

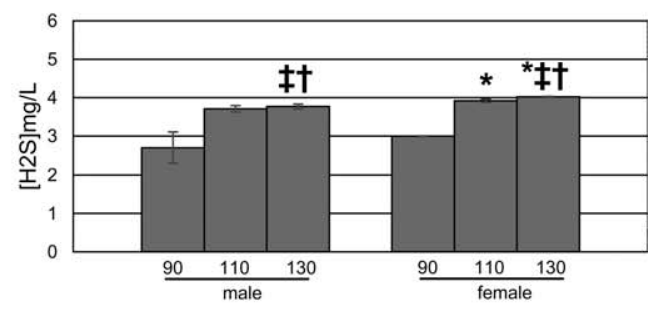

Motor cortex

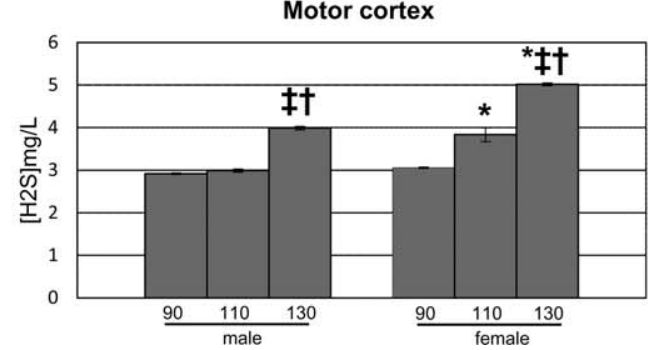

FIGURE 2: Hydrogen sulfide $\left(\mathrm{H}_{2} \mathrm{~S}\right)$ is significantly increased in the cerebral tissues of the SOD1G93A mice. (A) The figure shows significantly increased levels of $\mathrm{H}_{2} \mathrm{~S}$ in the SOD1G93A mice compared to the wild-type (WT) mice at 90, 110, and 130 days of age $\left(n=6\right.$ for each group; ${ }^{*} p<0.05$ ). (B) The figure shows a different $\mathrm{H}_{2} \mathrm{~S}$ tissue distribution between the 2 genders of SOD1G93A mice, with significant higher levels $\left({ }^{\star} p<0.05\right)$ in the female mice compared to the male mice in all the tissues analyzed (indicated in the figure). Moreover the SOD1G93A mouse shows significant $\mathrm{H}_{2} \mathrm{~S}$ content at 130 days compared to 90 $(\dagger p<0.05)$ and 110 days of age $(\neq p<0.05)$. Data are presented as mean \pm standard error of the mean; values were compared by using the Wilcoxon-Mann-Whitney test.

In the presence of the antimitotic agent Ara-C $(10 \mu \mathrm{M})$, to halt the growth of proliferating cells such as astrocytes, $\mathrm{H}_{2} \mathrm{~S}$ levels dropped significantly in the SOD1G93A cultures $(3.97 \mathrm{mg} / \mathrm{l})$ compared to the untreated ones. Notably, there was a negligible effect of astrocyte ablation in WT cultures. To complement the Ara-C data, SOD1G93A and WT cultures were treated with LPS (100ng/ml for 24 hours at 3 DIV) to activate microglia and induce inflammation. LPS treatment led to a significant increase in $\mathrm{H}_{2} \mathrm{~S}$ production in the fALS cultures compared to the control cultures (see Fig 4B). This increase was completely reverted by the concurrent administration of $500 \mu \mathrm{M}$ of the CBS inhibitor aminooxyacetate $(\mathrm{AOA})$, a concentration that in preliminary studies decreased significantly the levels of $\mathrm{H}_{2} \mathrm{~S}$ in the culture media (not shown) without being toxic for the motor neurons. Hence, in our system, $\mathrm{H}_{2} \mathrm{~S}$ seems to be related to a proinflammatory state, and CBS appears to be the main enzyme involved in its production.

\section{$\mathrm{H}_{2} \mathrm{~S}$ Is Toxic to Motor Neurons}

Having demonstrated increased $\mathrm{H}_{2} \mathrm{~S}$ production in mutant fALS spinal cord cultures, we then investigated whether $\mathrm{H}_{2} \mathrm{~S}$ mediates neurotoxicity to motor neurons. For this set of experiments, we used spinal cord cultures prepared from WT C57BL/6J mice. The $\mathrm{H}_{2} \mathrm{~S}$ donor $\mathrm{NaHS}^{49}$ was added to the medium at increasing concentrations for 18 hours (see Fig 4C-E). We observed a dose-dependent increase in SMI-32-positive neurons death starting at $100 \mu \mathrm{M}$, and reaching a complete motor neuron loss at $800 \mu \mathrm{M}$, while showing no toxicity to the GFAP-positive cells (not shown). Moreover, to evaluate the selectivity of the $\mathrm{H}_{2} \mathrm{~S}$-mediated toxicity to motor neurons, we examined the survival of the primary spinal GABAergic neurons. NaHS exposure was toxic to GABAergic neurons from a concentration as high as $600 \mu \mathrm{M}$ ( $\sim 60 \%$ death rate).

$\mathrm{H}_{2} \mathrm{~S}$ is known to induce neuronal death through the ionotropic glutamate receptors. ${ }^{31,50}$ Thus, we 
A
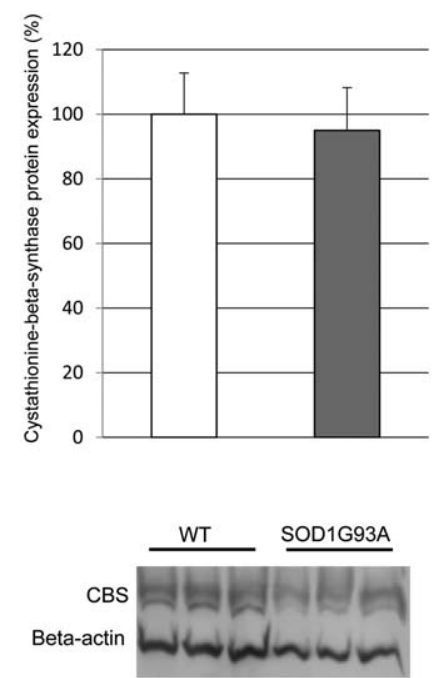

B
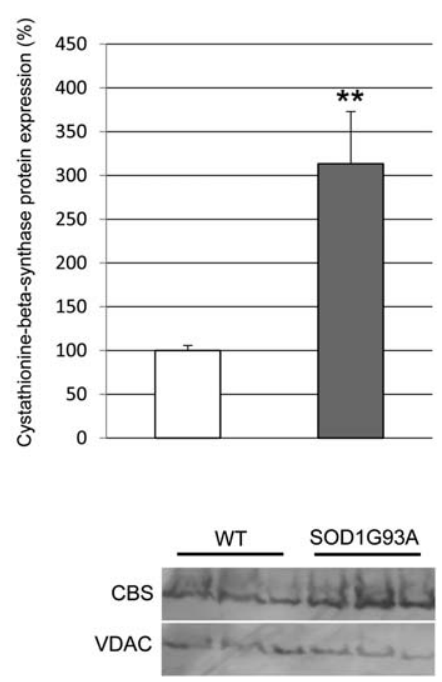

FIGURE 3: The cystathionine-ß-synthase (CBS) protein is localized in the mitochondria-enriched fraction. Western blot analysis of CBS is shown in the cytosol (A) and mitochondria-enriched fraction (B) from wild-type (WT) and SOD1G93A spinal cord. Whereas in the spinal cord cytosol fraction (A) there was no difference in the CBS protein expression between WT ( $n=5$ ) and SOD1G93A $(n=6)$, in the mitochondria-enriched fraction $(B)$, it increased in SOD1G93A $\left(n=10,{ }^{* *} p<0.01\right)$ compare to the WT $(n=8)$. The CBS expression of the SOD1G93A mice was plotted after the normalization with beta-actin in the cytosol fraction and with voltage-dependent anion-selective channel (VDAC) in the mitochondria-enriched fraction, in reference to the expression in the WT and presented as a ratio $(\times 100)$. The protein amount was $25 \mu \mathrm{g}$. Data are presented as mean \pm standard error of the mean, and values were compared by using Student $t$ test

reasoned that the $\mathrm{H}_{2} \mathrm{~S}$-dependent motor neuron death could be reverted by the inhibition of the glutamatergic ionotropic receptors. For this set of experiments, we used the concentration of $100 \mu \mathrm{M}$ NaHS that has shown a neuronal death rate of about 50\% (see Fig 4C). A comparison between NaHS alone and NaHS+MK801 $(10 \mu \mathrm{M})$, an NMDA receptor antagonist, or $\mathrm{NaHS}+\mathrm{CNQX}(25 \mu \mathrm{M})$, an AMPA/kainate antagonist, revealed a lack of protection of MK-801, but a rescue of about $18 \%$ cell survival using CNQX (see Fig 4D). Therefore, it seems that the $\mathrm{H}_{2} \mathrm{~S}$ toxicity is partially associated with the activation of the AMPA/kainate receptors. Motor neurons appear to be more susceptible than other neurons to AMPA receptor-mediated excitotoxicity. ${ }^{37,51}$

\section{$\mathrm{H}_{2} \mathrm{~S}$ Donor NaHS Elevates $\mathrm{Ca}^{2+}$ Concentration in Spinal Motor Neurons}

We measured cytosolic $\mathrm{Ca}^{2+}$ concentration $\left(\left[\mathrm{Ca}^{2+}\right]_{\mathrm{i}}\right)$ in response to $\mathrm{NaHS}$ in spinal motor neurons loaded with Fura-2 AM or with Fura-2 K5 via the patch pipette during electrophysiological recordings (Fig 5). Some neurons of either genotype (15 of 55) showed spontaneous lowfrequency $\quad(0.025 \pm 0.0032 \mathrm{~Hz}) \quad$ calcium waves in unclamped and voltage clamped $(-60 \mathrm{mV})$ conditions that were inhibited by TTX or lidocaine $(1$ or $200 \mu \mathrm{M}$, respectively) or APV and NBQX (50 and $10 \mu \mathrm{M}$, respectively), indicating that they were caused by an action potential-dependent synaptic release of glutamate from sur- rounding neurons. Resting $\mathrm{Ca}^{2+}$ levels were similar in WT and SOD1G93A neurons, being $0.33 \pm 0.007, \mathrm{n}=23$, and $0.33 \pm 0.006, \mathrm{n}=25$, respectively. Addition of $\mathrm{NaHS}$ $(300 \mu \mathrm{M})$ to the bath solution silenced the calcium waves and caused a slow onset $\mathrm{Ca}^{2+}$ rise up to $0.66 \pm 0.05$ and to $0.71 \pm 0.07$, after 30 minutes, in WT and SOD1G93A neurons, respectively. The intracellular $\mathrm{Ca}^{2+}$ accumulation partially recovered upon $\mathrm{NaHS}$ washout.

To test whether voltage-gated calcium channels (VGCCs) ${ }^{32,52}$ and/or ionotropic glutamate receptors ${ }^{53,54}$ mediated $\mathrm{Ca}^{2+}$ entry in motor neurons during the superfusion of NaHS, we performed $\left[\mathrm{Ca}^{2+}\right]_{\mathrm{i}}$ measures combined with patch clamp recordings (see Fig 5C-F) at holding potential of $-60 \mathrm{mV}$ (to prevent activation of voltage-dependent calcium channels) in the presence of AMPA and NMDA receptor antagonists. Under these conditions, NaHS $(300 \mu \mathrm{M})$ still caused a $\left[\mathrm{Ca}^{2+}\right]_{\mathrm{i}}$ increase from $0.57 \pm 0.06$ to $1.14 \pm 0.1 \quad(\mathrm{n}=11$, $p<0.001)$ and produced an inward current of $-45.7 \pm 10.93 \mathrm{pA}(\mathrm{n}=10$, see Fig 5 F, white bar) within 5 minutes. Both responses were similar in WT and SOD1G93A neurons, so the data were pulled together.

Interestingly, the NaHS-induced effects were strongly attenuated when the intracellular ATP concentration was increased to $2 \mathrm{mM}$ via the recording pipette (see Fig 5D-F). In response to NaHS application, $\left[\mathrm{Ca}^{2+}\right]_{\mathrm{i}}$ rose from $0.52 \pm 0.03$ to $0.66 \pm 0.06(\mathrm{n}=8$, $p<0.05)$ and mean current amplitude was $-29 \pm 4.8$ 
A

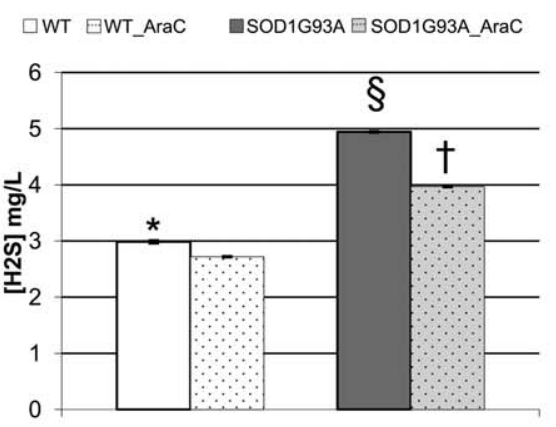

B

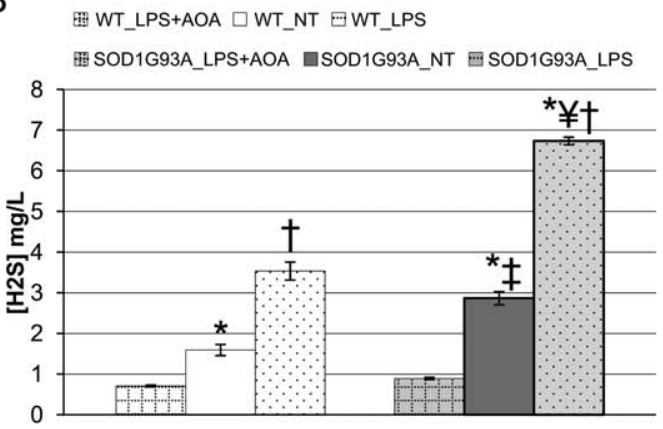

C

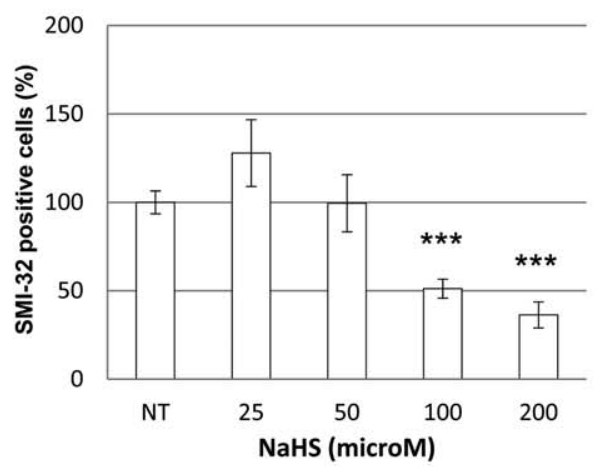

D

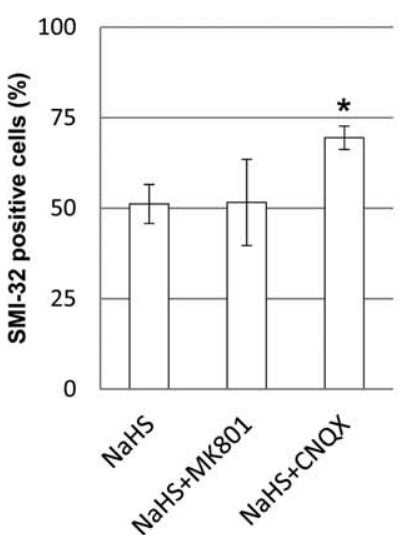

$\mathrm{E}$

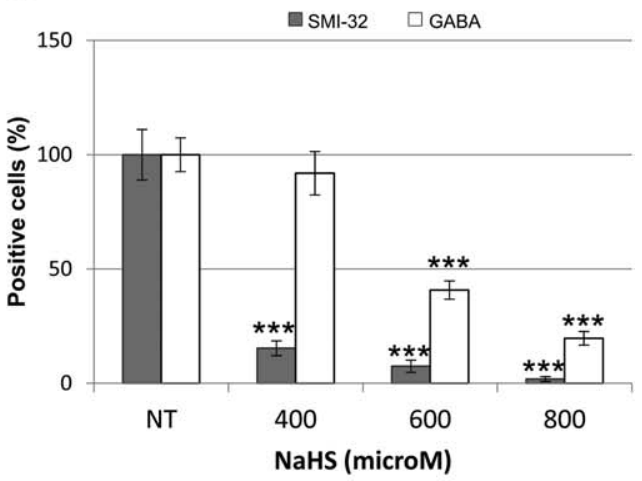

FIGURE 4: Hydrogen sulfide $\left(\mathrm{H}_{2} \mathrm{~S}\right)$ content is increased in mutant culture and is toxic to motor neurons. (A) Proteomic analysis of the culture media shows significantly higher concentration of $\mathrm{H}_{2} \mathrm{~S}$ in the mutant culture ( $n=6$; ${ }^{*} p<0.05$, wild type [WT] vs SOD1G93A) compared to the WT cultures $(n=3)$. Arabinoside $C($ Ara-C; $10 \mu M)$ treatment significantly decreased $\mathrm{H}_{2} S$ levels in the mutant culture $(n=6)$ compared to the WT $(n=3 ;+p<0.05$, SOD1G93A_AraC vs WT_AraC). Moreover, Ara-C treatment significantly decreased $\mathrm{H}_{2} \mathrm{~S}$ content in the mutant cultures ( $\$ p<0.05$, SOD1G93A vs SOD1G93A_AraC). Data are presented as mean \pm standard error of the mean (SEM). (B) Again proteomic analyses confirmed significantly higher concentration of $\mathrm{H}_{2} \mathrm{~S}$ in the mutant culture $(n=4)$ compared to the WT one $(n=6 ; \neq p<0.05$, SOD1G93A control vs WT). Lipopolysaccharide (LPS) treatment significantly increased $\mathrm{H}_{2} \mathrm{~S}$ concentration in the both WT $(n=4)$ and SOD1G93A cultures $(n=4)$ compared to the untreated ones of both genotypes ( $\dagger p<0.05$, WT LPS vs WT not treated [NT] and SOD1G93A LPS vs SOD1G93A not treated; $¥ p<0.05$, SOD1G93A LPS vs WT LPS). The administration of the cystathionine-ß-synthase inhibitor amino-oxyacetate (AOA) significantly decreased $\mathrm{H}_{2} \mathrm{~S}$ content in both cultures $\left(n=4\right.$ for each group; ${ }^{*} p<0.05$, WT not treated vs WT LPS + AOA and SOD1G93A not treated vs SOD1G93A LPS+AOA). Data are presented as mean \pm SEM. (C) Spinal cord cultures were exposed to the indicated concentrations of NaHS: $25 \mu \mathrm{M}(n=5), 50 \mu \mathrm{M}(n=4), 100 \mu \mathrm{M}(n=11, * \star \star p<0.005$ vs NT), and $200 \mu \mathrm{M}(n=4$, ${ }^{* \star *} p<0.005$ vs NT). (D) The cultures were exposed to NaHS $100 \mu \mathrm{M}$ plus MK801 $(10 \mu \mathrm{M} ; n=4)$ or 6-cyano-7-nitroquinoxaline2,3-dione (CNQX; $25 \mu \mathrm{M} ; n=5,{ }^{*} p<0.05$ ) to block $\mathrm{N}$-methyl-D-aspartate and $\alpha$-amino-3-hydroxy-5-methyl-4-isoxazole propionic acid/kainate receptors, respectively. After 18 hours, the number of surviving cells was assessed by direct counting of SMI32positive cells and normalized to the NT values $(n=14)$. (E) The cultures were exposed to the indicated concentrations of NaHS: $400 \mu \mathrm{M}(n=5), 600 \mu \mathrm{M}(n=5), 800 \mu \mathrm{M}(n=4)$ for 18 hours. The number of surviving cells was assessed by direct counting of cells positive for SMI-32 and $\gamma$-aminobutyric acid (GABA) and normalized to the NT values $(n=7)$. Each treatment was counted in triplicate. Data are presented as percentage and as mean \pm SEM. The values were compared by using post hoc Tukey test for $N$ unequal. ${ }^{* \star *} p<0.005$ vs NT.

( $\mathrm{n}=8$, see Fig 5F, black bar). This observation suggests that $\mathrm{Ca}^{2+}$ accumulation induced by NaHS in spinal neurons depends on a metabolic failure likely due to a drop of neuronal ATP.

\section{Discussion}

The present study analyzes the content of $\mathrm{H}_{2} \mathrm{~S}$ in ALS patients and highlights, for the first time, its potential role in this devastating disease. We found high levels of $\mathrm{H}_{2} \mathrm{~S}$ in the cephalorachidian fluid obtained from ALS patients. Moreover, $\mathrm{H}_{2} \mathrm{~S}$ levels were higher in the population of patients characterized by spinal cord onset compared to those with $\mathrm{BO}$. The different levels of $\mathrm{H}_{2} \mathrm{~S}$ encountered in the diverse types of onset of symptoms, being higher in patients with lumbar onset, could depend on the damaged area being larger at the lumbar level and 
A

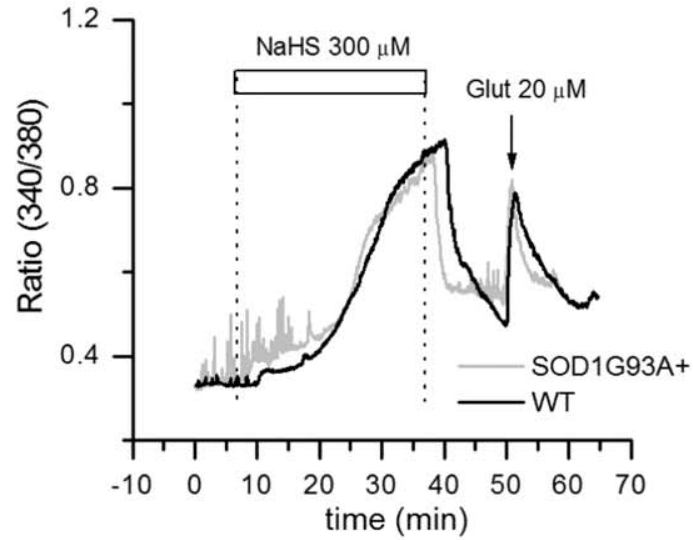

C
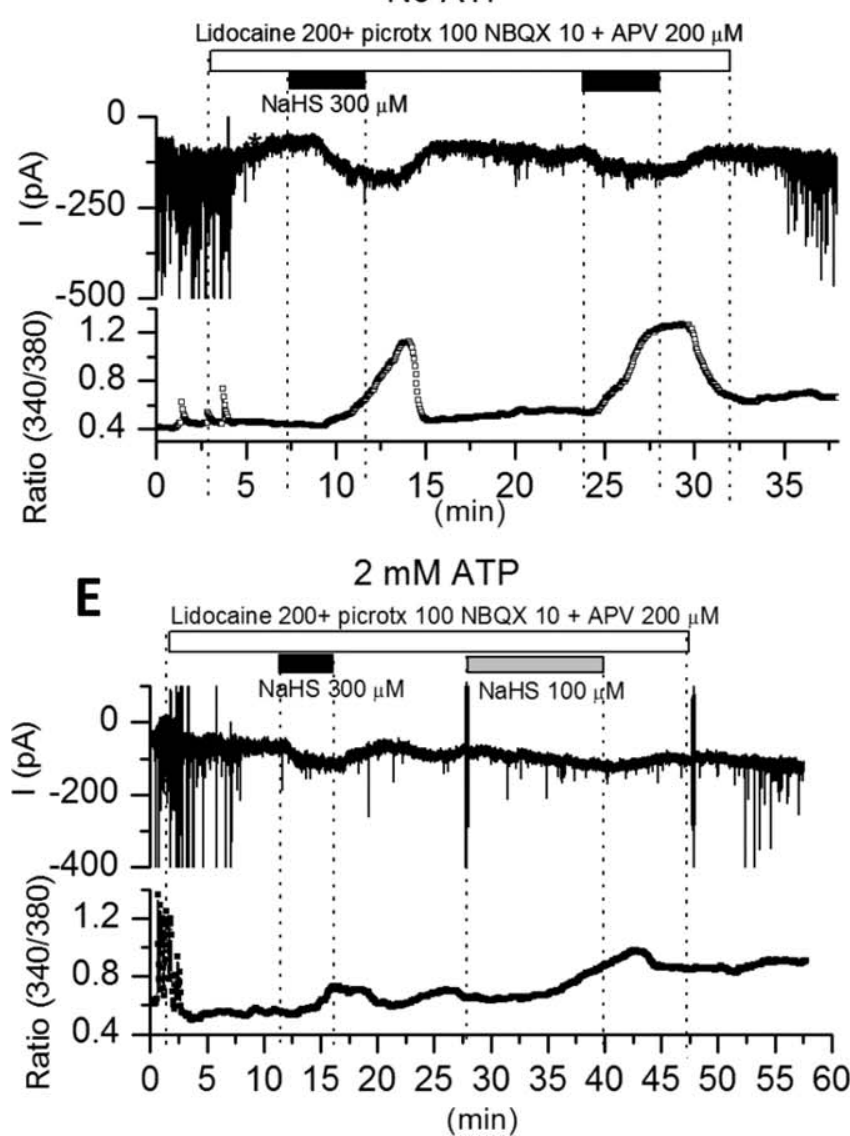

B

$\mathrm{NaHS} 300 \mu \mathrm{M}$

(30 min)

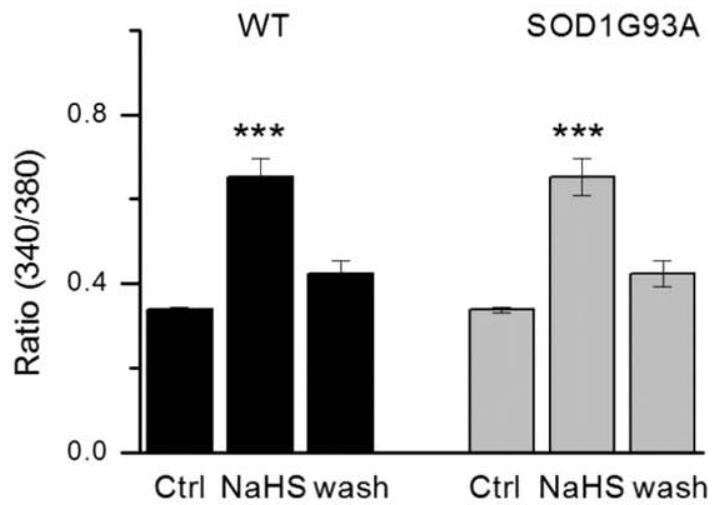

D

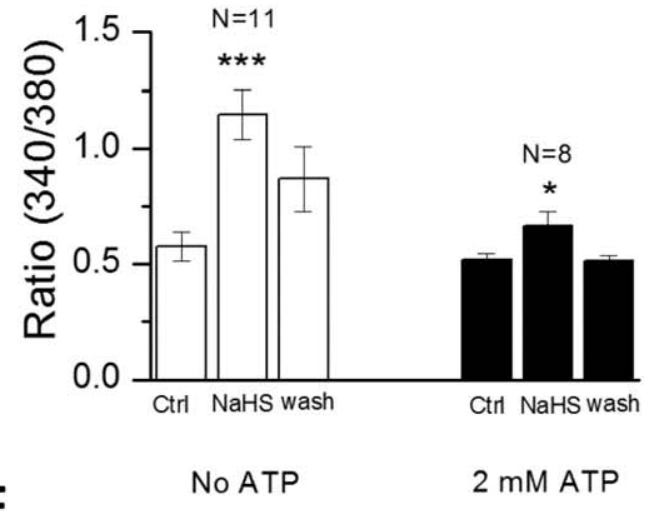

$\mathbf{F}$

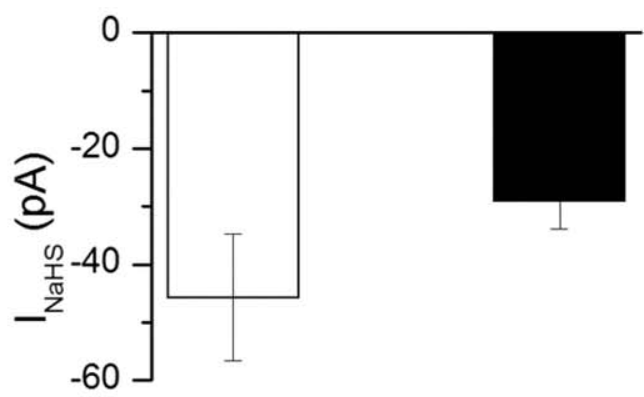

FIGURE 5: The $\left[\mathrm{Ca}^{2+}\right]_{i}$ accumulation induced by the hydrogen sulfide $\left(\mathrm{H}_{2} \mathrm{~S}\right)$ donor NaHS is adenosine triphosphate (ATP) dependent. (A) Time course of $\left[\mathrm{Ca}^{2+}\right]_{i}$ in response to NaHS perfusion $(300 \mu \mathrm{M})$ in wild-type (WT; C57BL/6J) and SOD1G93A spinal neurons loaded with Fura-2AM. NaHS application silenced the spontaneous $\mathrm{Ca}^{2+}$ transients and determined a slow onset $\left[\mathrm{Ca}^{2+}\right]_{i}$ rise, reaching a peak after 30 minutes of the $\mathrm{H}_{2} \mathrm{~S}$ donor application. Arrow indicates the increase in $\left[\mathrm{Ca}^{2+}\right]_{i}$ evoked by brief puffs of glutamate (Glut; $20 \mu \mathrm{M}$ ). (B) Bar graph showing mean levels of $\left[\mathrm{Ca}^{2+}\right]_{i}$ before, at 30 minutes, and after NaHS addition $(30$ minutes, $300 \mu \mathrm{M})$ in WT and SOD1G93A spinal neurons ( $\left.{ }^{* * *} p<0.001\right)$. The increase partially recovered after the NaHS washout. (C) Sample traces of voltage-clamp recordings $\left(V_{\text {hold }}=-60 \mathrm{mV}\right.$, top) combined with microfluorometry (bottom) showing that bath application of NaHS was still inducing a transient $\left[\mathrm{Ca}^{2+}\right] \mathrm{i}$ increase $(p<0.001)$ in the presence of a cocktail of channel and receptor blockers. (D, E) These responses were significantly attenuated when ATP (2mM) was added to the pipette solution. Histograms show mean changes of $\left[\mathrm{Ca}^{2+}\right]_{\mathrm{i}}\left({ }^{*} p<0.05, \mathrm{D}\right)$ and $I_{\mathrm{NaHS}}$ amplitude (F) in response to NaHS bath application in the absence ( $n=8$, white bars) or presence $(n=11$, black bars) of $2 \mathrm{mM}$ ATP. Data are presented as mean \pm SEM, and values were compared by using Student $t$ test. $p<0.001$ vs Ctrl. 
on the source of $\mathrm{H}_{2} \mathrm{~S}$ (if it mainly originates from the affected tissue) eventually being more proximal to the point of lumbar puncture. Interestingly, we also report that the sera content of $\mathrm{H}_{2} \mathrm{~S}$ is not elevated in ALS patients with respect to control subjects, which implies that this gas is specifically increased in the central nervous system. Moreover, the presence of a slight correlation between $\mathrm{H}_{2} \mathrm{~S}$ levels in the CSF and the progression rate of the disease could suggest a possible prognostic role, by indicating the speediness and severity of the pathological process.

$\mathrm{H}_{2} \mathrm{~S}$ is increasingly recognized as an important biological gaseous transmitter. At low concentrations, it has been proposed as a neuromodulator and neuroprotectant. ${ }^{55-57}$ It has important roles in the regulation of physiological functions including learning and memory ${ }^{11,55,58}$ and helps to suppress oxidative stress. ${ }^{59,60}$ In sharp contrast, based on the data presented herein, toxic effects seem to prevail in ALS. This toxicity most likely depends on its excessive concentration that, as a result, affects cellular functions.

In parallel, when we analyzed the levels of $\mathrm{H}_{2} \mathrm{~S}$ in the cerebral tissues of the fALS mouse model SOD1G93A, we found significantly increased levels of the gas, providing further proof of a distorted $\mathrm{H}_{2} \mathrm{~S}$ metabolism in ALS. Moreover, that $\mathrm{H}_{2} \mathrm{~S}$ is increased in both human sporadic ALS and in mouse fALS reveals that $\mathrm{H}_{2} \mathrm{~S}$ reaches harmful concentrations in ALS regardless of whether it has a genetic origin. Our study also unveils a significant accumulation of CBS in the mitochondrial-enriched fraction prepared from the spinal cords of fALS mice, which is likely associated with the increased production of $\mathrm{H}_{2} \mathrm{~S}$ in mitochondria. ${ }^{42} \mathrm{H}_{2} \mathrm{~S}$ inhibits complex IV (cytochrome c oxidase) of the mitochondrial respiratory chain. ${ }^{61}$ Noticeably, impairments in the complex IV-driven respiration have been described in the SOD1G93A mouse even before disease onset. ${ }^{62}$ Hence, the higher concentration of $\mathrm{H}_{2} \mathrm{~S}$ at end-stage in the fALS mouse (130 days) foresees a loop where the continuous increase of $\mathrm{H}_{2} \mathrm{~S}$ amount, reaching toxic levels, further distresses an already compromised mitochondrial function.

In this context, we found that the $\mathrm{H}_{2} \mathrm{~S}$ donor $\mathrm{NaHS}$ causes an increase of $\left[\mathrm{Ca}^{2+}\right]_{i}$ in single motor neurons, possibly due to inhibition of mitochondrial metabolism. Enhancing effects of NaHS on intracellular $\mathrm{Ca}^{2+}$ homeostasis have been reported in different cell types including cerebellar granule cells, ${ }^{32}$ spinal cord plus dorsal root ganglion, ${ }^{52}$ SHSY5Y, ${ }^{54}$ astrocytes, ${ }^{15}$ and microglia. ${ }^{63}$ It has been reported that this gasotransmitter activates $\mathrm{Ca}^{2+}$ entry via VGCCs and/or NMDA receptors, ${ }^{11}$ and this in turn triggers $\mathrm{Ca}^{2+}$ release from the endoplasmic reticulum. ${ }^{54}$ Here we present evidence that experimental conditions aimed at preventing VGCCs and ionotropic glutamate receptor activation did not inhibit $\left[\mathrm{Ca}^{2+}\right]_{\mathrm{i}}$ accumulation induced by NaHS in WT and SOD1G93A spinal neurons. Moreover, when additional ATP was supplied to the cytoplasm via the patch pipette, the NaHS-induced $\left[\mathrm{Ca}^{2+}\right]_{i}$ rise was strongly reduced. These experiments support the view that mechanisms other than VGCCs and glutamate receptor activation contribute to $\left[\mathrm{Ca}^{2+}\right]_{\mathrm{i}}$ accumulation in spinal motor neurons exposed to NaHS. ${ }^{64}$ Thus, based on our results, $\mathrm{H}_{2} \mathrm{~S}$ by blocking the mitochondrial respiratory chain reduces the energy supply to the cells (ATP) and increases intracellular calcium through defects of $\left[\mathrm{Ca}^{2+}\right]_{\mathrm{i}}$ ATPase extruding pump and by enhancing $\mathrm{Ca}^{2+}$ release from mitochondria. In neuronal types expressing ATPdependent potassium channels, by reducing intracellular ATP content, NaHS strongly activates this conductance. ${ }^{65}$ In both mouse genotypes the $\left[\mathrm{Ca}^{2+}\right]_{\mathrm{i}}$ responses occurred rapidly and were transient and comparable. This is a rather critical observation, because abnormalities in $\mathrm{Ca}^{2+}$ homeostasis, probably closely interconnected with mitochondrial pathology, ${ }^{5,66,67}$ have been described in ALS. ${ }^{38,68}$ In our experimental context, the finding that the $\left[\mathrm{Ca}^{2+}\right]_{\mathrm{i}}$ increase was comparable between control and SOD1G93A cultures implies that the neuronal responsiveness to $\mathrm{H}_{2} \mathrm{~S}$ is not altered in the mutant motor neurons. Instead, the overproduction of $\mathrm{H}_{2} \mathrm{~S}$ found in sporadic patients (CSF data), fALS mouse tissues, and media obtained from mutant primary culture indicates that in ALS $\mathrm{H}_{2} \mathrm{~S}$ reaches toxic concentration, facilitating neuronal death. This evidence supports the hypothesis that in the spinal motor neurons of ALS patients, constantly exposed to high endogenous $\mathrm{H}_{2} \mathrm{~S}$ concentrations, a partial mitochondrial disturbance could occur, mimicking a chronic hypoxic condition. This interpretation is also supported by a previous report showing that similarly to $\mathrm{H}_{2} \mathrm{~S}$, cyanide, another inhibitor of mitochondrial complex IV, causes disturbance in $\left[\mathrm{Ca}^{2+}\right]_{i}$ and activates inward membrane currents in motor neurons. ${ }^{69}$ Moreover, the disruption of intracellular $\mathrm{Ca}^{2+}$ homeostasis in ALS affects $\mathrm{Ca}^{2+}$ binding proteins such as calbindinD28K and parvalbumin ${ }^{70,71}$ as well as major $\mathrm{Ca}^{2+}$. dependent folding proteins such as calreticulin and calnexin. ${ }^{68}$ In this context, it is intriguing to hypothesize that $\mathrm{H}_{2} \mathrm{~S}$, by affecting $\left[\mathrm{Ca}^{2+}\right]_{\mathrm{i}}$, can in turn modify not only the neurons ability to cope with $\mathrm{Ca}^{2+}$ alterations but also interfere with proper protein folding, thus reinforcing a self-amplifying vicious cycle in the vulnerable neurons. Furthermore, $\mathrm{H}_{2} \mathrm{~S}$ appears to interact at different levels with nitric oxide (NO), another gaseous transmitter known to be involved in ALS pathology. ${ }^{72} \mathrm{H}_{2} \mathrm{~S}$ 
and NO seem to affect their enzymatic production, and also to interact further downstream, at the level of their metabolites. ${ }^{73}$ Moreover, the link between calreticulin expression and the motor neuron-specific Fas/NO pathway has been recently demonstrated. ${ }^{74}$ Taken together, these findings delineate an array of interconnected signaling pathways potentially linking a number of ALS-related pathogenic mechanisms affecting both neurons and glial cells.

Astrocytes are the most important producers of $\mathrm{H}_{2} \mathrm{~S}$ in the brain, followed by microglia. ${ }^{13}$ In ALS, nonneuronal cells play a critical role in the neurodegeneration and many authors have shown that astrocytes can provoke spontaneous degeneration of motor neurons. $^{70-73}$ Hence, we reasoned that reactive astrocytes could be the main source of $\mathrm{H}_{2} \mathrm{~S}$ in our system. In keeping with this possibility, we halted glial cell proliferation in vitro. Under this condition, we measured significantly low levels of $\mathrm{H}_{2} \mathrm{~S}$, thus demonstrating that glia cells are an important source of $\mathrm{H}_{2} \mathrm{~S}$, even more in the mutant cultures. Those observations are backed by treatment with LPS, to induce microglia activation, resulting in an increased production of $\mathrm{H}_{2} \mathrm{~S}$ in both genotypes, particularly in the mutant. Interestingly, the massive activation of astrocytes and microglia in ALS elevates the production of inflammatory markers and proinflammatory cytokines, ${ }^{74}$ suggesting that $\mathrm{H}_{2} \mathrm{~S}$ is produced by astrocytes and is generated during the inflammatory processes that are present in ALS.

$\mathrm{H}_{2} \mathrm{~S}$ is an ambivalent biological agent with a biphasic dose--response curve and opposing effects, depending on its concentration. ${ }^{31}$ At low concentrations (nanomolar/low micromolar), $\mathrm{H}_{2} \mathrm{~S}$ stimulates mitochondrial functions, is an anti-inflammatory agent, protects against oxidative stress, and improves cell viability. ${ }^{75}$ At higher concentrations (mid to high micromolar), $\mathrm{H}_{2} \mathrm{~S}$ is a proinflammatory agent, suppresses cell viability, promotes cell death (necrosis/apoptosis), and inhibits mitochondrial function. ${ }^{75}$ Thus, we may infer that $\mathrm{H}_{2} \mathrm{~S}$ overproduction, most likely due to reactive gliosis occurring in ALS, contributes to the ALS-related neuronal death. We also document that application of $\mathrm{H}_{2} \mathrm{~S}$ kills motor neurons at relatively low concentrations compared to GABAergic neurons. Motor neurons are highly compartmentalized cells with large soma ( $>20 \mu \mathrm{m}$ diameter). Moreover, their extraordinary axonal tree, relatively fast firing rate during muscle activation, and rapidly conducting axons, with high metabolic demands, also contribute to their greater energy requirements. Hence, this result indicates that, as a blocker of the mitochondrial respiratory chain, $\mathrm{H}_{2} \mathrm{~S}$ impairs cellular energy production more effectively in an energy-needing cell like the motor neuron.
In conclusion, our data suggest that $\mathrm{H}_{2} \mathrm{~S}$ is probably a player in the mechanisms of non-cell-autonomous motor neuron death as one of the end-products of glial activation. That we have measured higher levels of $\mathrm{H}_{2} \mathrm{~S}$ in the spinal cord and brainstem (the two most affected areas in this fALS model) is consistent with the hypothesis that $\mathrm{H}_{2} \mathrm{~S}$ is released by glial cells during inflammation.

Our study introduces $\mathrm{H}_{2} \mathrm{~S}$ as a new actor to the cohort of proinflammatory/degenerative factors that could be involved in the etiology of ALS. Its pathogenic significance needs to be further assessed as a likely contributor to non-cell-autonomous motor neuron death, a characteristic trait of ALS.

\section{Authorship}

A.D., V.G., and A.S. contributed equally to this article. N.B.M., A.U., and P.L. contributed equally to this article.

\section{Potential Conflicts of Interest}

Nothing to report.

\section{References}

1. Rowland LP, Shneider NA. Amyotrophic lateral sclerosis. N Engl J Med 2001;344:1688-1700.

2. Turner MR, Hardiman $\mathrm{O}$, Benatar $\mathrm{M}$, et al. Controversies and priorities in amyotrophic lateral sclerosis. Lancet Neurol 2013;12: 310-322.

3. Rothstein JD. Current hypotheses for the underlying biology of amyotrophic lateral sclerosis. Ann Neurol 2009;65(suppl 1):S3-S9.

4. Robberecht W, Philips T. The changing scene of amyotrophic lateral sclerosis. Nat Rev Neurosci 2013;14:248-264.

5. Cozzolino M, Carrì MT. Mitochondrial dysfunction in ALS. Prog Neurobiol 2012;97:54-66.

6. Turner MR, Kiernan MC, Leigh PN, Talbot K. Biomarkers in amyotrophic lateral sclerosis. Lancet Neurol 2009;8:94-109.

7. Peers C, Bauer CC, Boyle JP, et al. Modulation of ion channels by hydrogen sulfide. Antioxid Redox Signal 2012;17:95-105.

8. Singh S, Padovani D, Leslie RA, et al. Relative contributions of cystathionine beta-synthase and gamma-cystathionase to $\mathrm{H} 2 \mathrm{~S}$ biogenesis via alternative trans-sulfuration reactions. J Biol Chem 2009;284:22457-22466.

9. Kabil O, Banerjee R. Enzymology of H2S biogenesis, decay and signaling. Antioxid Redox Signal 2014;20:770-782.

10. Shibuya N, Koike S, Tanaka M, et al. A novel pathway for the production of hydrogen sulfide from D-cysteine in mammalian cells. Nat Commun 2013;4:1366.

11. Abe K, Kimura $\mathrm{H}$. The possible role of hydrogen sulfide as an endogenous neuromodulator. J Neurosci 1996;16:1066-1071.

12. Qu K, Lee SW, Bian JS, et al. Hydrogen sulfide: neurochemistry and neurobiology. Neurochem Int 2008;52:155-165.

13. Lee M, Schwab C, Yu S, et al. Astrocytes produce the antiinflammatory and neuroprotective agent hydrogen sulfide. Neurobiol Aging 2009;30:1523-1534. 
14. Kimura H. Hydrogen sulfide: its production, release and functions. Amino Acids 2011;41:113-121.

15. Nagai $Y$, Tsugane M, Oka J, Kimura H. Hydrogen sulfide induces calcium waves in astrocytes. FASEB J 2004;18:557-559.

16. Enokido $Y$, Suzuki E, Iwasawa $K$, et al. Cystathionine betasynthase, a key enzyme for homocysteine metabolism, is preferentially expressed in the radial glia/astrocyte lineage of developing mouse CNS. FASEB J 2005;9:1854-1856.

17. Tay AS, Hu LF, Lu M, et al. Hydrogen sulfide protects neurons against hypoxic injury via stimulation of ATP-sensitive potassium channel/protein kinase C/extracellular signal-regulated kinase/heat shock protein 90 pathway. Neuroscience 2010;167:2772-2786.

18. Liang $\mathrm{GH}$, Adebiyi $\mathrm{A}$, Leo MD, et al. Hydrogen sulfide dilates cerebral arterioles by activating smooth muscle cell plasma membrane KATP channels. Am J Physiol Heart Circ Physiol 2011;300: H2088-H2095.

19. Liu WQ, Chai C, Li XY, et al. The cardiovascular effects of central hydrogen sulfide are related to K(ATP) channels activation. Physiol Res 2011:60:729-738.

20. Hu LF, Wong PT, Moore PK, Bian JS. Hydrogen sulfide attenuates lipopolysaccharide-induced inflammation by inhibition of p38 mitogen-activated protein kinase in microglia. J Neurochem 2007; 100:1121-1128.

21. Liu YY, Bian J. Hydrogen sulfide protects amyloid-beta induced cell toxicity in microglia. J Alzheimers Dis 2010;22:1189-1200.

22. Lu M, Hu LF, Hu G, Bian JS. Hydrogen sulfide protects astrocytes against $\mathrm{H}(2) \mathrm{O}(2)$-induced neural injury via enhancing glutamate uptake. Free Radic Biol Med 2008;45:1705-1713.

23. Hu LF, Lu M, Wu ZY, et al. Hydrogen sulfide inhibits rotenoneinduced apoptosis via preservation of mitochondrial function. Mol Pharmacol 2009;75:27-34.

24. Tiong CX, Lu M, Bian JS. Protective effect of hydrogen sulphide against 6-OHDA-induced cell injury in $\mathrm{SH}-\mathrm{SY} 5 \mathrm{Y}$ cells involves PKC/PI3K/Akt pathway. Br J Pharmacol 2010;161:467-480.

25. Hu LF, Lu M, Tiong CX, et al. Neuroprotective effects of hydrogen sulfide on Parkinson's disease rat models. Aging Cell 2010;9:135146.

26. Kida K, Yamada M, Tokuda K, et al. Inhaled hydrogen sulfide prevents neurodegeneration and movement disorder in a mouse model of Parkinson's disease. Antioxid Redox Signal 2011;15:343352.

27. Giuliani D, Ottani A, Zaffe D, et al. Hydrogen sulfide slows down progression of experimental Alzheimer's disease by targeting multiple pathophysiological mechanisms. Neurobiol Learn Mem 2013; 104:82-91.

28. He $X L$, Yan $N$, Zhang $H$, et al. Hydrogen sulfide improves spatial memory impairment and decreases production of A $\beta$ in APP/PS1 transgenic mice. Neurochem Int 2014;67:1-8.

29. Ren C, Du A, Li D, et al. Dynamic change of hydrogen sulfide during global cerebral ischemia-reperfusion and its effect in rats. Brain Res 2010;1345:197-205.

30. Li GF, Luo HK, Li LF, et al. Dual effects of hydrogen sulphide on focal cerebral ischaemic injury via modulation of oxidative stressinduced apoptosis. Clin Exp Pharmacol Physiol 2012;39:765-771.

31. Cheung NS, Peng ZF, Chen MJ, et al. Hydrogen sulfide induced neuronal death occurs via glutamate receptor and is associated with calpain activation and lysosomal rupture in mouse primary cortical neurons. Neuropharmacology 2007;53:505-514.

32. García-Bereguiaín MA, Samhan-Arias AK, Martín-Romero FJ, Gutiérrez-Merino C. Hydrogen sulfide raises cytosolic calcium in neurons through activation of L-type $\mathrm{Ca} 2+$ channels. Antioxid Redox Signal 2008;10:31-42.
33. Kimura $F$, Fujimura $C$, Ishida $S$, et al. Progression rate of ALSFRS$\mathrm{R}$ at time of diagnosis predicts survival time in ALS. Neurology 2006;66:265-267.

34. Spalloni A, Geracitano R, Berretta N, et al. Molecular and synaptic changes in the hippocampus underlying superior spatial abilities in pre-symptomatic G93A+/+ mice overexpressing the human $\mathrm{Cu} / \mathrm{Zn}$ superoxide dismutase (Gly93 -> ALA) mutation. Exp Neurol 2006;197:505-514.

35. Bailey B, Waraska J, Acworth I. Direct determination of tissue aminothiol, disulfide, and thioether levels using HPLC-ECD with a novel stable boron-doped diamond working electrode. Methods Mol Biol 2010;594:327-339.

36. Malkus KA, Ischiropoulos H. Regional deficiencies in chaperonemediated autophagy underlie $\alpha$-synuclein aggregation and neurodegeneration. Neurobiol Dis 2012;46:732-744.

37. Spalloni A, Albo F, Ferrari F, et al. Cu/Zn-superoxide dismutase (GLY93->ALA) mutation alters AMPA receptor subunit expression and function and potentiates kainate-mediated toxicity in motor neurons in culture. Neurobiol Dis 2004;15:340-350.

38. Guatteo E, Carunchio I, Pieri M, et al. Altered calcium homeostasis in motor neurons following AMPA receptor but not voltagedependent calcium channels' activation in a genetic model of amyotrophic lateral sclerosis. Neurobiol Dis 2007;28:90-100.

39. Guatteo E, Federici M, Siniscalchi A, et al. Whole cell patch-clamp recordings of rat midbrain dopaminergic neurons isolate asulphonylurea- and ATP-sensitive component of potassium currents activated by hypoxia. J Neurophysiol 1998;79:1239-1245.

40. Gurney ME, Pu H, Chiu AY, et al. Motor neuron degeneration in mice that express a human $\mathrm{Cu}, \mathrm{Zn}$ superoxide dismutase mutation. Science 1994;264:1772-1775.

41. Wiliński B, Wiliński J, Somogyi E, et al. Metformin raises hydrogen sulfide tissue concentrations in various mouse organs. Pharmacol Rep 2013;65:737-742.

42. Teng $\mathrm{H}, \mathrm{Wu} B$, Zhao $\mathrm{K}$, et al. Oxygen-sensitive mitochondrial accumulation of cystathionine $\beta$-synthase mediated by Lon protease. Proc Natl Acad Sci U S A 2013;110:12679-12684.

43. Schiffman PL, Belsh JM. Pulmonary function at diagnosis of amyotrophic lateral sclerosis. Rate of deterioration. Chest 1993;103: 508-513.

44. Atalaia A, Carvalho MD, Evangelista T, Pinto A. Sleep characteristics of amyotrophic lateral sclerosis in patients with preserved diaphragmatic function. Amyotroph Lateral Scler 2007;8:101-105.

45. Murakami $\mathrm{T}$, llieva $\mathrm{H}$, Shiote $\mathrm{M}$, et al. Hypoxic induction of vascular endothelial growth factor is selectively impaired in mice carrying the mutant SOD1 gene. Brain Res 2003;989:231-237.

46. Van Den Bosch L, Storkebaum E, Vleminckx V, et al. Effects of vascular endothelial growth factor (VEGF) on motor neuron degeneration. Neurobiol Dis 2004;17:21-28.

47. Greenway MJ, Andersen PM, Russ C, et al. ANG mutations segregate with familial and 'sporadic' amyotrophic lateral sclerosis. Nat Genet 2006:38:411-413.

48. Sebastià J, Kieran D, Breen B, et al. Angiogenin protects motoneurons against hypoxic injury. Cell Death Differ 2009;16:12381247

49. Łowicka E, Bełtowski J. Hydrogen sulfide (H2S) the third gas of interest for pharmacologists. Pharmacol Rep 2007;59:4-24.

50. Chen MJ, Peng ZF, Manikandan J, et al. Gene profiling reveals hydrogen sulphide recruits death signaling via the $\mathrm{N}$-methyl-Daspartate receptor identifying commonalities with excitotoxicity J Cell Physiol 2011;2265:1308-1322.

51. Corona JC, Tapia R. Ca2+-permeable AMPA receptors and intracellular $\mathrm{Ca} 2+$ determine motoneuron vulnerability in rat spinal cord in vivo. Neuropharmacology 2007;52:1219-1228. 
52. Maeda $Y$, Aoki $Y$, Sekiguchi $F$, et al. Hyperalgesia induced by spinal and peripheral hydrogen sulfide: evidence for involvement of Cav3.2 T-type calcium channels. Pain 2009;142:127-132.

53. Kimura $\mathrm{H}$. Hydrogen sulfide induces cyclic AMP and modulates the NMDA receptor. Biochem Biophys Res Commun 2000;267: 129-133.

54. Yong $\mathrm{QC}$, Choo $\mathrm{CH}$, Tan $\mathrm{BH}$, et al. Effect of hydrogen sulfide on intracellular calcium homeostasis in neuronal cells. Neurochem Int 2010:56:508-515

55. Kimura $\mathrm{H}$. Hydrogen sulfide as a neuromodulator. Mol Neurobiol 2002;26:13-19.

56. Tan BH, Wong PT, Bian JS. Hydrogen sulfide: a novel signaling molecule in the central nervous system. Neurochem Int 2010;56: $3-10$.

57. Zhou CF, Tang XQ. Hydrogen sulfide and nervous system regulation. Chin Med J (Engl) 2011;124:3576-3582.

58. Eto K, Ogasawara M, Umemura K, et al. Hydrogen sulfide is produced in response to neuronal excitation. J Neurosci 2002;22: 3386-3391.

59. Kimura $Y$, Kimura $H$. Hydrogen sulfide protects neurons from oxidative stress FASEB J 2004;18:1165-1167.

60. Kimura $Y$, Goto $Y$, Kimura H. Hydrogen sulfide increases glutathione production and suppresses oxidative stress in mitochondria. Antioxid Redox Signal 2010;12:1-13.

61. Módis K, Bos EM, Calzia E, et al. Regulation of mitochondrial bioenergetic function by hydrogen sulfide. Part II. Pathophysiological and therapeutic aspects. Br J Pharmacol 2014;171:2123-2146.

62. Kirkinezos IG, Bacman SR, Hernandez D, et al. Cytochrome c association with the inner mitochondrial membrane is impaired in the CNS of G93A-SOD1 mice. J Neurosci 2005;25:164-172.

63. Lee SW, Hu YS, Hu LF, et al. Hydrogen sulphide regulates calcium homeostasis in microglial cells. Glia 2006;54:116-124.

64. Andersson DA, Gentry C, Bevan S. TRPA1 has a key role in the somatic pro-nociceptive actions of hydrogen sulfide. PLoS One 2012; 7:e46917.
65. Kimura $Y$, Dargusch $R$, Schubert $D$, Kimura $H$. Hydrogen sulfide protects HT22 neuronal cells from oxidative stress. Antioxid Redox Signal 2006;8:661-670.

66. Grosskreutz J, Van Den Bosch L, Keller BU. Calcium dysregulation in amyotrophic lateral sclerosis. Cell Calcium 2010;47:165-174.

67. Duffy LM, Chapman AL, Shaw PJ, Grierson AJ. The role of mitochondria in the pathogenesis of amyotrophic lateral sclerosis Neuropathol Appl Neurobiol 2011;37:336-352.

68. Prell T, Lautenschläger J, Grosskreutz J. Calcium-dependent protein folding in amyotrophic lateral sclerosis. Cell Calcium 2013;54: $132-143$

69. Bergmann F, Keller BU. Impact of mitochondrial inhibition on excitability and cytosolic $\mathrm{Ca} 2+$ levels in brainstem motoneurones from mouse. J Physiol 2004;555:45-59

70. Laslo P, Lipski J, Nicholson LF, et al. Calcium binding proteins in motoneurons at low and high risk for degeneration in ALS. Neuroreport 2000;11:3305-3308

71. Sasaki S, Warita H, Komori T, et al. Parvalbumin and calbindin D 28k immunoreactivity in transgenic mice with a G93A mutant SOD1 gene. Brain Res 2006;1083:196-203.

72. Lewis KE, Rasmussen AL, Bennett W, et al. Microglia and moto neurons during disease progression in the SOD1G93A mouse model of amyotrophic lateral sclerosis: changes in arginase 1 and inducible nitric oxide synthase. J Neuroinflammation 2014 11:55

73. Bertova A, Cacanyiova S, Kristek F, et al. The hypothesis of the main role of $\mathrm{H} 2 \mathrm{~S}$ in coupled sulphide-nitroso signalling pathway. Gen Physiol Biophys 2010;29:402-410.

74. Bernard-Marissal N, Moumen A, Sunyach C, et al. Reduced calreticulin levels link endoplasmic reticulum stress and Fas-triggered cell death in motoneurons vulnerable to ALS. J Neurosci 2012;32: 4901-4912.

75. Cassina P, Pehar M, Vargas MR, et al. Astrocyte activation by fibroblast growth factor-1 and motor neuron apoptosis: implications for amyotrophic lateral sclerosis. J Neurochem 2005;93: $38-46$. 